\title{
The pandemic push: can COVID-19 reinvent conferences to models rooted in sustainability, equitability and inclusion?
}

\author{
Holly J. Niner ${ }^{1}$ (D) . Shaili Johri ${ }^{2}$ D . Judith Meyer ${ }^{3}$ (D) S Sophia N. Wassermann ${ }^{4}$ D
}

Received: 3 June 2020 / Accepted: 30 July 2020

(c) The Author(s) 2020

\begin{abstract}
The COVID-19 pandemic necessitates a change in conference formats for 2020. This shift offers a unique opportunity to address long-standing inequities in access and issues of sustainability associated with traditional conference formats, through testing online platforms. However, moving online is not a panacea for all of these concerns, particularly those arising from uneven distribution of access to the Internet and other technology. With conferences and events being forced to move online, this is a critical juncture to examine how online formats can be used to best effect and to reduce the inequities of in-person meetings. In this article, we highlight that a thoughtful and equitable move to online formats could vastly strengthen the global socio-ecological research community and foster cohesive and effective collaborations, with ecology and society being the ultimate beneficiaries.
\end{abstract}

Keywords Equitable access $\cdot$ Sustainability $\cdot$ Inclusion $\cdot$ Diversity $\cdot$ Knowledge exchange $\cdot$ Virtual conference $\cdot$ Online conference

\section{A window of opportunity}

International conferences are valued as important for the development of both researchers and knowledge (Fraser et al. 2017, p. 540; Timperley et al. 2020, pp. 11-12). Yet, the traditional conference model that brings delegates

Judith Meyer

jmeyer@kms.uni-kiel.de

Holly J. Niner

holly.niner@plymouth.ac.uk

Shaili Johri

shailij@stanford.edu

Sophia N. Wassermann

s.wassermann1@nuigalway.ie

1 School of Biological and Marine Sciences, Floor 3, Marine Building, University of Plymouth, Drake Circus, Plymouth PL4 8AA, UK

2 Hopkins Marine Station, Department of Biology, Stanford University, 120 Oceanview Boulevard, Pacific Grove, CA 93950, USA

3 Centre for Ocean and Society, Christian-Albrechts-University Kiel, Neufeldtstraße 10, 24118 Kiel, Germany

4 Ryan Institute, School of Natural Sciences, National University of Ireland, Galway, University Rd., Galway H91 TK33, Ireland together in a single 'destination' demands costly international travel and often high registration fees. Given the associated carbon emissions and inequities in access, there is a particularly strong moral onus for those engaged in the field of socio-ecology to develop conference models or practices that do not contribute to the very problems that the discipline seeks to address.

The forcing hand of COVID-19 has opened an opportunity to trial online formats and to reinvent conferences as a core institution of research and practice. A global rise in community goodwill and flexibility in response to the challenges of 'lockdown' (Morgan 2020) provides an opportunity to address some of the long-term ethical quandaries that relate to both sustainability and accessibility (Ford et al. 2018; Arend and Bruijns 2019; Timperley et al. 2020) posed by traditional conference formats.

\section{Inequities of in-person conferences}

Equal participation at conferences is restricted by access to financial support for travel and registration fees. The costs of visas, flights, registration and accommodation are an insurmountable obstacle for many involved in socioecological practice (Xiang 2019) and research. Funding for attendance is frequently limited for those in practitioner 
positions outside of the academy and those based in lowincome nations (Fullick 2016; Waruru 2018). In our experience organising several non-profit international socio-ecological conferences, raising finance to support attendance in constrained funding landscapes remains challenging, despite the ethical and moral imperatives to diversify participation.

Beyond access, societies have moved to address issues of inequality faced by participants. These efforts include codes of conducts to manage in-conference interaction (Favaro et al. 2016), mentoring (Timperley et al. 2020, p. 12), childcare provision, employing mediators to manage disputes and incentivising leadership roles and participation of historically and structurally marginalised groups including women, people of colour, those with physical and mental health disabilities, and LGBTQ+(e.g. IMCC5 2017).

Additionally, travelling internationally to a conference is not sustainable. Some conferences offset their participants' travel emissions (Holden et al. 2017, p. 1211). However, the compensation of carbon emissions is controversial and, according to the carbon management hierarchy, should only be used as a last resort after exhausting all other options for mitigation (Hyams and Fawcett 2013, p. 93).

\section{Inequities of online conferences}

Online conference formats remove the need for travel and reduce the costs of attendance, but they do not preclude inequality in access and participation. New challenges are posed by a move online, such as replicating the much valued spontaneous and informal opportunities of traditional in-person conferences, where non-verbal cues are more easily detected (Fish et al. 1993, p. 46; Erickson 2011, p. 508). Furthermore, the different norms of interaction in an online setting may exacerbate inequalities in participation. For instance, online communication is often associated with a degradation in politeness (Hardaker 2010, p. 238). Cultural insensitivity and impoliteness are known causes of lower levels of minority faculty representation in the academy (Louque and Thompson 2005, p. 38 and p. 233). Accordingly, online communication may make it harder for inexperienced or minority community members to establish themselves in a global network of colleagues. This may have long-term impacts on the diversity and innovation potential of the socio-ecological research community.

Another immediate issue is access to technology and infrastructure for online participation. Minority participants likely experience the digital divide disproportionately. For example, only $42 \%$ of urban households in India have Internet access, dropping to $14.9 \%$ for rural households
(Government of India 2018 p.47). Further, primary users of the Internet in India are male (36\%) with only $16 \%$ of women having access to mobile Internet, the primary mode of digital connectivity (GSMA 2019, p. 15). This underlying disparity in digital access is partially neutralised by reliable Internet access for those engaged at a subset of governmental, private and higher education institutes. However, with the current shelter-in-place restrictions, institutional access is restricted, forcing users to rely on in-home or mobile Internet, which is frequently unavailable, with only $23.4 \%$ of urban households having access to a computer (Government of India 2018, p. 47). Access is likely even worse for conservation practitioners based in rural settings globally and for students 'sent home' from universities. In Africa in March 2020, only 39.3\% of the total population could access the Internet, compared to the rest of the world at $62.9 \%$, with smartphone access at 51\% in South Africa, 30\% in Kenya and extremely low at 13\% in Tanzania (Ngware 2020).

Increasing global access to the Internet is central to achieving the UN sustainable development goals, and a shift to online conferences supports this aim. However, increasing access will increase the carbon emissions associated with the Internet, which are estimated to exceed those of the aviation industry (Boston Consulting Group 2012, pp. 9-13; Malmodin and Lundén 2018, pp. 26-29). Evidently, 'going online' does not completely neutralise the carbon emissions of a conference (Taylor 2020). As such, accounting for the carbon footprint of conferences remains relevant for online formats, but could legitimately meet the demands of the carbon management hierarchy.

\section{Supporting an equitable online future}

The COVID-19 pandemic offers an opportunity to understand and demonstrate how online platforms can address issues of equity in access and sustainability. The elimination of travel costs clearly reduces the barriers to participation as long as conference registration fees associated with inperson events are similarly reduced. However, engagement online must be fostered to allow online formats to confer the same value as traditional formats. Additionally, the associated technological requirements could risk widening the inequities for participants who are already the most disadvantaged in the socio-ecological community (Martin 2012; UN News 2020).

A key 'entry cost' to participation remains in the issue of technology access and Internet infrastructure. While many conference participants may have adequate access to Internet and technology, to address issues of diversity, equity and inclusion, online platform selection should consider associated requirements for high bandwidth, high-performing 
devices and training in these technologies. In the absence of uniform digital access, conferences can make use of a variety of more widely available technologies, such as dissemination of conference content in recorded, live and audio-only formats accessible via telephone, radio (Ngware 2020), podcasts and other popular smartphone applications such as WhatsApp (Bouhnik and Deshen 2014, pp. 217-220; Taru 2020).

Meeting format can address inequalities in participation, but success will depend on community goodwill to actively engage in the programme. Formats can be adapted to support the cultivation of 'social presence' through careful consideration of scheduling around time zones, and a combination of live and recorded presentations and interactive events, such as live question and answer sessions or break out groups (Tu and McIsaac 2010). Mentorship and clear communication of expectations of engagement as set out by a code of conduct could also assist in supporting aims of equitable inclusion and in providing space for all voices to be heard. The optimal model for online conferences may differ more drastically from the in-person format. Rather than large, immersive conferences held over a set time period, it could include perennial platforms (e.g. professional societies or established communication hubs) integrating a range of technologies that host 'special issues' or informal networking events. These 'smaller' yet more frequent events may ensure active and sustained participation across geographic and disciplinary sectors, ensuring a true diverse and inclusive conference model.

\section{Conclusions}

The potential to address long-standing inequities in the socio-ecological community through online conferences is a bright spot in the post-COVID-19 landscape. For now, online formats tend to follow the traditions of in-person conferences, being focussed over a defined period and based around thematically grouped presentations or posters. The current pandemic has led to a shift in forms of communication (Taru 2020; Wen 2020), and as people adapt to forging and maintaining relationships online rather than in person, innovation of the conference model to avoid the risks of continuing or exacerbating issues of inclusion and access online will be key.

The reinvention of conferences required by COVID19 shows us that there are viable options for professional and knowledge development that do not sit at odds with ambitions for an equitable and sustainable future. However, this reinvention must carefully consider the requirements for equitable access and will depend on ongoing and enthusiastic engagement of audiences. As the COVID-19 response challenges the need for and moral standing of the traditional conference, we have been given an opportunity to experiment and begin to explore what works best for all sectors of society.

Funding Open Access funding provided by Projekt DEAL.

Open Access This article is licensed under a Creative Commons Attribution 4.0 International License, which permits use, sharing, adaptation, distribution and reproduction in any medium or format, as long as you give appropriate credit to the original author(s) and the source, provide a link to the Creative Commons licence, and indicate if changes were made. The images or other third party material in this article are included in the article's Creative Commons licence, unless indicated otherwise in a credit line to the material. If material is not included in the article's Creative Commons licence and your intended use is not permitted by statutory regulation or exceeds the permitted use, you will need to obtain permission directly from the copyright holder. To view a copy of this licence, visit http://creativecommons.org/licenses/by/4.0/.

\section{References}

Arend ME, Bruijns SR (2019) Disparity in conference registration cost for delegates from low- and middle-income backgrounds. Afr J Emerg Med 9(3):156-161. https://doi.org/10.1016/j.afjem .2019 .01 .016

Boston Consulting Group (2012) GeSI SMARTer 2020: the role of ICT in driving a sustainable future. https://www.bcg.com/publi cations/2012/energy-environment-technology-industries-smart er-2020-role-ict-driving-sustainable-future.aspx

Bouhnik D, Deshen M (2014) WhatsApp goes to school: mobile instant messaging between teachers and students. J Inf Technol Educ: Res 13:217-231. https://doi.org/10.28945/2051

Erickson T et al (2011) Synchronous interaction among hundreds: An evaluation of a conference in an avatar-based virtual environment. In: Proceedings of conference on human factors in computing systems. pp 503-512. https://doi.org/10.1145/1978942.1979013

Favaro B et al (2016) Your science conference should have a code of conduct. Front Mar Sci 3:1-4. https://doi.org/10.3389/fmars .2016 .00103

Fish RS et al (1993) Video as a technology for informal communication. Commun ACM 36(1):48-61. https://doi.org/10.1145/15123 3.151237

Ford HL et al (2018) Gender inequity in speaking opportunities at the American Geophysical Union Fall Meeting. Nat Commun 9(1):3-8. https://doi.org/10.1038/s41467-018-03809-5

Fraser $\mathrm{H}$ et al (2017) The value of virtual conferencing for ecology and conservation. Conserv Biol 31(3):540-546. https://doi. org/10.1111/cobi.12837

Fullick M (2016) It's time to rethink academic conference funding, University Affairs. https://www.universityaffairs.ca/opinion/specu lative-diction/its-time-to-re-think-academic-conference-funding. Accessed 28 May 2020

Government of India (2018) Key indicators of household social consumption on education in India: NSS 75th Round. Delhi. http:// www.mospi.gov.in/sites/default/files/publication_reports/KI_ Education 75th Final.pdf

GSMA (2019) The Mobile Gender Gap Report 2019. https://www. gsma.com/mobilefordevelopment/wp-content/uploads/2019/03/ 
GSMA-Connected-Women-The-Mobile-Gender-Gap-Repor t-2019.pdf

Hardaker C (2010) Trolling in asynchronous computer-mediated communication: from user discussions to academic definitions. J Polit Res 6(2):215-242. https://doi.org/10.1515/jplr.2010.011

Holden MH et al (2017) Academic conferences urgently need environmental policies. Nat Ecol Evol 1(9):1211-1212. https://doi. org/10.1038/s41559-017-0296-2

Hyams K, Fawcett T (2013) The ethics of carbon offsetting. Wiley Interdiscipl Rev Clim Change 4(2):91-98. https://doi.org/10.1002/ wcc. 207

IMCC5 (2017) 20\% Registration discount for female symposium leaders at IMCC5, SCB Marine. https://imcc2018.wordpress. com/2017/09/29/20-registration-discount-for-female-symposiumleaders-at-imcc5. Accessed: 28 May 2020

Louque AC, Thompson GL (2005) Exposing the "culture of Arrogance" in the academy: a blueprint for increasing black faculty satisfaction in higher education. Stylus Publishing, Sterling

Malmodin J, Lundén D (2018) The energy and carbon footprint of the global ICT and E \& M sectors 2010-2015. Sustain (Switzerland) 10(9):1. https://doi.org/10.3390/su10093027

Martin LJ (2012) Where are the women in ecology? Front Ecol Environ 10(4):177-178. https://doi.org/10.1890/12.wb.011

Morgan C (2020) As coronavirus shrinks our world, resurgent community spirit offers hope, The Guardian. https://www.theguardia n.com/society/2020/apr/21/community-spirit-hope-coronaviru s-public-services. Accessed 28 May 2020

UN News (2020) Startling disparities in digital learning emerge as COVID-19 spreads: UN education agency. UN News 21 April. https://news.un.org/en/story/2020/04/1062232. Accessed: 28 May 2020

Ngware M (2020) Delivering education online: coronavirus underscores what's missing in Africa, The Conversation. https://theco nversation.com/delivering-education-online-coronavirus-under scores-whats-missing-in-africa-134914. Accessed 28 May 2020

Taru J (2020) Digital tragedy: doing online teaching in Zimbabwe during the pandemic. Corona Times. https://www.coronatimes.net/ digital-tragedy-zimbabwe-pandemic/

Taylor ARE (2020) Why going digital in pandemic times might not be as green as you think. Corona Times. https://www.coronatime s.net/going-digital-not-as-green-covid-19/

Timperley $\mathrm{C}$ et al (2020) He moana pukepuke: navigating gender and ethnic inequality in early career academics' conference attendance. Gender Educ 32(1):11-26. https://doi.org/10.1080/09540 253.2019.1633464

Tu C, McIsaac M (2010) The relationship of social presence and interaction in online classes the relationship of social presence and interaction. Communication 16(3):131-150. https://doi. org/10.1207/s15389286ajde1603

Waruru M (2018) African and Asian researchers are hampered by visa problems. Nature. https://doi.org/10.1038/d41586-018-06750-1

Wen T (2020) How coronavirus has transformed the way we communicate. BBC, April. https://www.bbc.com/worklife/article/20200 408-coronavirus-how-lockdown-helps-those-who-fear-the-phone

Xiang W-N (2019) Ecopracticology: the study of socio-ecological practice. Socio-Ecological Practice Research. Springer Singapore 1(1):7-14. https://doi.org/10.1007/s42532-019-00006-6

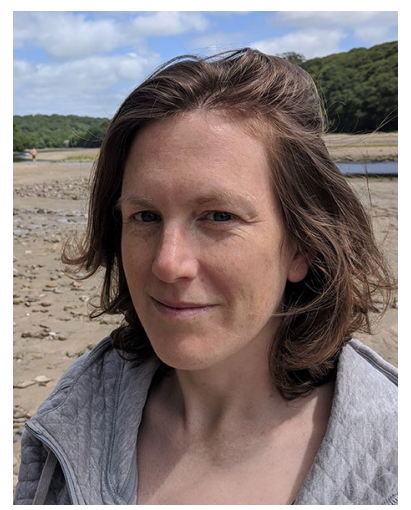

Dr. Holly Niner is a research and knowledge exchange fellow working on the One Ocean Hub at the University of Plymouth. Through her work, she seeks to support the sustainable, equitable and just use of marine and coastal resources and space. She is a co-chair of IMCC6.

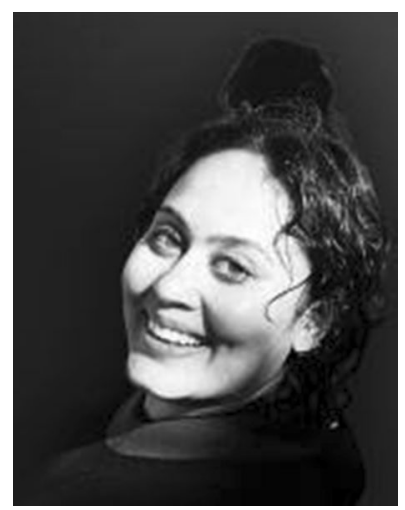

Dr. Shaili Johri (Ph.D. Genetics) is pursuing postdoctoral work at Stanford University with a research focus on conservation genomics of marine wildlife. In her capacity as the Diversity Officer of the Society for Conservation Biology Marine Section, Shaili engages in addressing issues of diversity, equity and inclusion affecting conservation research/practice.

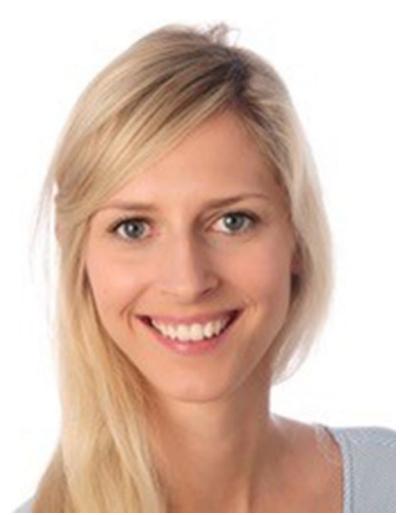

Dr. Judith Meyer holds a Ph.D. in Biological Oceanography. After a 3-year postdoc position at GEOMAR Helmholtz Centre for Ocean Research Kiel, she transitioned into science management in 2019 and is now employed as scientific project manager at the Center for Ocean and Society in Kiel, Germany.

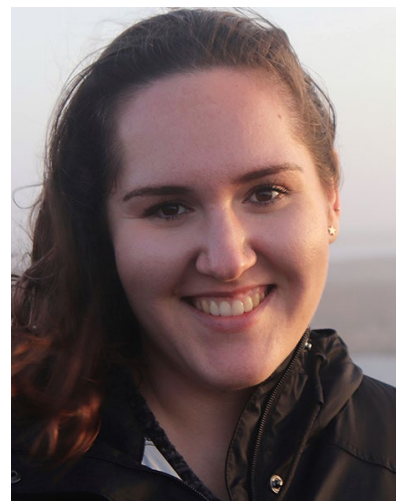

Sophia Wassermann is in the last few months of her Ph.D. in Marine Science at the National University of Ireland, Galway. Her research focuses on applying theoretical concepts and quantitative methods to practical issues in fisheries and ecosystem sustainability. She is a co-chair of IMCC6. 